IZA DP No. 9649

Does It Pay to Care?

Prosocial Engagement and Employment Opportunities

Stijn Baert

Sunčica Vujić

January 2016

Forschungsinstitut zur Zukunft der Arbeit Institute for the Study of Labor 


\title{
Does It Pay to Care? Prosocial Engagement and Employment Opportunities
}

\author{
Stijn Baert \\ Ghent University, University of Antwerp, \\ Université catholique de Louvain and IZA
}

Sunčica Vujić

University of Antwerp

and University of Bath

\section{Discussion Paper No. 9649 \\ January 2016}

\author{
IZA \\ P.O. Box 7240 \\ 53072 Bonn \\ Germany
}

Phone: +49-228-3894-0

Fax: +49-228-3894-180

E-mail: iza@iza.org

Any opinions expressed here are those of the author(s) and not those of IZA. Research published in this series may include views on policy, but the institute itself takes no institutional policy positions. The IZA research network is committed to the IZA Guiding Principles of Research Integrity.

The Institute for the Study of Labor (IZA) in Bonn is a local and virtual international research center and a place of communication between science, politics and business. IZA is an independent nonprofit organization supported by Deutsche Post Foundation. The center is associated with the University of Bonn and offers a stimulating research environment through its international network, workshops and conferences, data service, project support, research visits and doctoral program. IZA engages in (i) original and internationally competitive research in all fields of labor economics, (ii) development of policy concepts, and (iii) dissemination of research results and concepts to the interested public.

IZA Discussion Papers often represent preliminary work and are circulated to encourage discussion. Citation of such a paper should account for its provisional character. A revised version may be available directly from the author. 


\section{ABSTRACT \\ Does It Pay to Care? \\ Prosocial Engagement and Employment Opportunities*}

We investigate whether, why and when prosocial engagement has a causal effect on individual employment opportunities. To this end, a field experiment is conducted in which volunteering activities are randomly assigned to fictitious job applications sent to genuine vacancies. We find that volunteers get one third more interview invitations than non-volunteers. The volunteering premium is higher for females but invariant with respect to the number of engagements and the private versus public or nonprofit orientation of the job posting firm. As a result, our findings are consistent with the idea that prosocial workers sort themselves into non-commercial sectors.

JEL Classification: $\quad$ C93, D64, J24, J71

Keywords: prosocial behaviour, volunteering, labour market, gender gaps, statistical discrimination, sorting, experiments

Corresponding author:

Stijn Baert

Ghent University

Sint-Pietersplein 6

9000 Gent

Belgium

E-mail: Stijn.Baert@UGent.be 


\section{Introduction}

Prosocial engagement is a widespread phenomenon in OECD countries. On average, 23.4\% of respondents in the sixth round of the European Social Survey (ESS6) in 2012/2013 reported that they were involved in work for voluntary or charitable organisations at least once every six months. As seen in Figure 1, statistics on volunteering in Europe are both stable over time and heterogeneous across countries. Whereas in 2012/2013 in Germany, the Netherlands, Norway and Switzerland, more than $40 \%$ of ESS6 respondents volunteered, in Bulgaria and Hungary, less than $10 \%$ engaged at least once every sixth months in prosocial work. Given the substantial amount of prosocial engagement, economists have unsurprisingly shown a renewed interest over the past decade in the economic consequences of these types of activities, from both society's and individuals' point of view (see, e.g., Binder and Freytag, 2013; Carpenter and Myers, 2010; Cozzi et al., 2013; Meier and Stutzer, 2008; Sauer, 2015). In the present study, we focus on the causal effect of prosocial engagement with respect to individuals' (paid) employment opportunities.

\section{FIGURE 1 ABOUT HERE.}

Theoretically, there are three channels through which prosocial engagement might affect one's labour market outcomes: human capital, social capital and employer preferences. Based on these channels, both beneficial and adverse effects of prosocial engagement on employment outcomes are possible. First, volunteer work may directly enhance individuals' human capital by providing them with an alternative way to acquire skills and experience. Following standard Human Capital Theory (Becker, 1964; Mincer, 1958), these skills and experience may lead to additional returns on the labour market (Becker, 1964; Day and Devlin, 1997; Day and Devlin, 1998). However, based on the same theory in combination with the Theory of the Allocation of Time (Becker, 1965), a negative effect might also be expected because maintaining substantial volunteering schemes may interfere with time investments in hard skills. Second, according to Social Network Theory 
(Granovetter, 1973), during volunteer work, socially engaged people may expand their networks, which might help them find a better job match more quickly (Sauer, 2015). Thirdly and finally, prosocial engagement might affect employers' hiring and promotion decisions even when prosocial activities do not affect employees' human or social capital. On the one hand, following Becker's (1957) taste-based discrimination model, employers may prefer (not) to hire prosocially engaged job candidates just because these employers, their co-workers or customers experience a certain (dis)utility from working together with these prosocially engaged people. On the other hand, following Arrow's (1973) model of statistical discrimination, employers might use social engagement on applicants' résumés to screen and sort job seekers according to abilities that are unobserved by these employers. In this respect, social engagement is related in the peer-reviewed literature to personality traits such as emotional stability, extraversion and openness (Bekkers, 2005; Elshaug and Metzer, 2010), which are shown to enhance individual productivity and team performance (Barrick and Mount, 1991; Costa and McCrae, 1992; Heineck, 2011; Tett et al., 1991; Uysal and Pohlmeier, 2011). However, prosocial behaviour might also be perceived as a signal of a lower focus on regular employment given the aforementioned time trade-off between prosocial activities and regular work.

We are aware of six previous studies by economists that confronted the aforementioned theoretical expectations with the empirical reality: Cozzi et al. (2013), Day and Devlin (1997), Day and Devlin (1998), Hackl et al. (2007), Prouteau and Wolff (2006) and Sauer (2015). Table 1 summarises the research results published, between 1997 and 2015, either as a journal article or as a working paper. As shown in Table 1, these studies were conducted based on data for Austria, Canada (two studies), France, the United Kingdom and the United States. Remarkably, all these studies found statistically significant effects of volunteer work on income. ${ }^{1}$ However, the wage premium found varied considerably, i.e., from $2.6 \%$ to $94.7 \%$.

TABLE 1 ABOUT HERE.

\footnotetext{
${ }^{1}$ One exception is the finding of a decrease in current earnings by $1.7 \%$ for volunteers in the subgroup of workers in the private sector in France (Prouteau and Wolff, 2006).
} 
We see two important gaps in the mentioned empirical literature on the effect of volunteering on individuals' labour market outcomes. First, it is doubtful whether the published results can be given a causal interpretation. All these studies rely on survey data in which the treatment of prosocial engagement is not randomly assigned to individuals. Job applicants, who appear similar to researchers based on these survey data apart from their prosocial engagement, might have significantly different characteristics in reality. As long as not all variables driving hiring, remuneration and promotion decisions that may correlate with prosocial behaviour (such as family formation, ambition, personality traits, political ideology and ability) are controlled by the researcher, analyses might suffer from selection bias. As shown in the last column of Table 1, several econometric strategies were employed to control for this endogeneity problem. The most ambitious approaches were, in our opinion, taken by Sauer (2015) on the one hand and Cozzi et al. (2013) and Hackl et al. (2007) on the other hand. Sauer (2015) estimated a structural (discrete dynamic choice programming) model in which employment state, marital status and fertility were modelled jointly. However, as for any study employing a structural model, causal inference in their study hinged crucially on the validity of their model design and the parametrisation of this model, which is hard to test. Cozzi et al. (2013) and Hackl et al. (2007) employed an instrumental variable approach. The former authors chose rainfall across area districts as an instrument, and the latter chose club membership during youth and a volunteering partner for their exclusion restrictions. A key identifying assumption for their estimation results to be causal was that these instruments might not correlate with other determinants of labour market outcomes that are not controlled for. Particularly with respect to the instruments used by Hackl et al. (2007), this is questionable because both instruments may correlate with, for instance, social skills, social networks and personality traits. In addition, as acknowledged by Cozzi et al. (2013) when interpreting their result of a wage premium from volunteering amounting to $94.7 \%$, instrumental variable estimates isolate a local average treatment effect (LATE), i.e., a wage premium among individuals who are directly affected in their volunteering decision by the chosen instrument(s) (Angrist et al., 2000). 
In addition to the uncertainty about the causal interpretation of the answer the aforementioned studies gave to the question whether volunteering causally affects employment outcomes, these studies are inconclusive about why work for free may pay off. In other words, no study has focussed on explicitly examining the empirical salience of the three theoretical channels outlined above. However, knowing an answer to this why question would be particularly interesting for charity organisations to learn how they can stimulate potential involvement and for governments to learn how they can intervene to foster prosocial engagement because it is socially desirable (Prouteau and Wolff, 2006).

In the present study, we aim to fill (part of) both gaps by providing the first (field) experimental estimates on the labour market returns to volunteering. More concretely, we run a randomised field experiment in which pairs of fictitious job applications are sent to real vacancies. For each vacancy, one of the two applications is randomly assigned to a treatment of prosocial engagement. Due to this experimental design, selection into prosocial engagement on the basis of individual unobservable characteristics is eliminated because the researcher controls all the information received by the employer. Therefore, unequal treatment of volunteers and non-volunteers can be due only to their revealed social engagement.

Moreover, our research design enables us to provide suggestive evidence with respect to the empirical power of the aforementioned theoretical channels underlying the effect of prosocial engagement on later employment opportunities. Because strict equivalence between fictitious applicants is ensured and because, by construction, they apply for positions with an employer outside their network, a nonzero treatment effect can indicate only that the theoretical channel with respect to employer preferences (taste and statistical discrimination) plays a role in this respect.

In addition, we contribute to the literature by looking into three dimensions of heterogeneous treatment effects of prosocial engagement (i.e., when working for free yields a higher (or lower) premium). First, we inspect whether the returns to volunteering in hiring are heterogeneous by gender. Former empirical evidence on gender differentials indicates higher premiums for males. Day and Devlin (1997) and 
Cozzi et al. (2013) found that men have larger returns to volunteer experience than women and that these differential returns can explain a substantial part of the gender earnings gap. However, given the non-experimental nature of their data, none of these studies is able to fully control for the non-random assignment of women and men to different types of volunteer organisations and different types of activities undertaken, yielding different skills, networks and appreciation by employers. ${ }^{2}$ Consequently, the gender differentials in returns to volunteering found in Day and Devlin (1997) and Cozzi et al. (2013) might just reflect the non-random way in which females and males select themselves into types of volunteering. ${ }^{3}$ Due to our experimental setting, in which we alternate between female and male pairs, we force the assignment of different types of volunteering activities to female and male job candidates to be perfectly random.

Second, whereas most of the aforementioned studies investigate only the effect of having ever volunteered making abstraction of the intensity of the engagement, our experimental design allows us to investigate the relative effect of different doses of volunteer work (i.e., one, two or three prosocial engagements). More activity might yield a stronger signal of (beneficial qualities related to) volunteering and a stronger signal of an overly low focus on paid regular work (given the aforementioned time trade-off between both activities).

Finally, we inspect whether returns to prosocial engagement are higher in public and non-profit firms than in commercial firms. Traditionally, the rate of volunteer participation has been found to be higher in the public and non-profit sector than in the private sector (Bandiera, 2014; Prouteau and Wolff, 2006; Rotolo and Wilson, 2006). The question is whether this phenomenon is because prosocial employees are attracted to the societal goals of non-commercial organisations and, ipso facto,

\footnotetext{
${ }^{2}$ At best, Day and Devlin (1997) added some organisation-type dummies to their linear regressions to control for this issue.

${ }^{3}$ Day and Devlin (1997) and Dittrich and Mey (2015) show, indeed, that women in Canada and Germany spend more time performing volunteer work at religious organisations or organisations that help the poor or the elderly, whereas men are more active in recreational organisations and service clubs, such as the Rotary Club. Exploratory analyses by Day and Devlin (1997) indicate that the latter types of volunteering are more rewarded in the labour market.
} 
sort themselves into these organisations (Francois and Vlassopoulos, 2008; Jacobsen et al., 2011; Kolstad and Lindkvist, 2013), or whether employers in the public and non-profit sector are more likely than for-profit employers to rely on intrinsically (socially) motivated employees because of their unique organisational needs, with a strong desire for the generation of social benefits (Leete, 2000). Because we test vacancies in both the commercial and non-commercial sectors, we are able to shed some light on the latter mechanism. Thereby, we try to fill part of the gap in the literature, identified by Bandiera et al. (2011), on matching between firms and employees based on their respective characteristics, including prosocial values. ${ }^{4}$ Our research also extends the literature on self-selection and sorting in the labour market and the effects of prosocial behaviour (Besley and Ghatak, 2005; Gregg et al. 2011; Lagarde and Blaauw, 2014) and, by extension, non-cognitive skills on labour market outcomes (Borghans et al., 2008; Fortin, 2008; OECD, 2015).

The remainder of this study is structured as follows. In the following section, we present our experimental design, which aims to evaluate the effect of prosocial engagement on employers' hiring decisions, keeping observable human and social capital constant. In Section 3, we answer our research questions by means of a statistical examination of the experimentally gathered data. A final section concludes and acknowledges some research limitations.

\section{The Experiment}

To answer our research question, we built on the correspondence experimentation framework of Bertrand and Mullainathan (2004), which has been recently used and calibrated by Baert et al. (2015), Kroft et al. (2013) and Eriksson and Rooth (2014),

\footnotetext{
${ }^{4}$ This matching on social values is theorised in other fields such as psychology and management under the labels "Commitment Model", "Attraction-Selection-Attrition" and "Multilevel Fit in Selection" (Anderson et al., 2004; Baron and Hannan, 2002; Schneider, 1987). The red line through these theories indicates that successful hiring policies focus on strong complementarities in social values on the work floor. Prosocial aspects of one's résumé might provide a guiding tool in this direction.
} 
among others. Within this type of experiment, pairs of fictitious job applications are sent to real job openings. The fictitious applications only differ in the characteristic (the experimental "treatment") that is to be tested. By monitoring subsequent callback, unequal treatment based on this characteristic ("treatment effect") can be identified. This method is the golden standard for measuring unequal treatment in hiring because selection on unobservables is not an issue; the researcher controls all the employer's decision-making information (Pager, 2007; Riach and Rich, 2002).

We conducted our experiment between December 2014 and April 2015. During this period, we sent pairs of fictitious job applications to real vacancies in Flanders, the Northern part of Belgium, ${ }^{5}$ posted by commercial and non-commercial organisations. For each vacancy, we randomly assigned two identities with respect to volunteering (one control and one treated identity) to each member of the pairs of applicants. In addition to this within-pair randomisation of prosocial engagement, to inspect heterogeneous treatment effects, the female or male gender (equal for both pair members) and different combinations of three types of prosocial engagement (for the treated applicant within the pairs) were randomly assigned between the pairs of applicants. Thereafter, reactions from the employers were analysed to investigate the surplus ${ }^{6}$ from different types of volunteering for different types of individuals in different types of sectors. ${ }^{7}$

\subsection{Application Templates}

In contrast to many former correspondence experiments in which applications were

\footnotetext{
${ }^{5}$ Based on the ESS6 data mentioned in the introduction, the level of volunteering in Belgium is slightly above the average level across all respondents in Europe. More concretely, 27.0\% of the surveyed Belgians in the ESS6 data reported having undertaken volunteer work during the previous six months (see Figure 1).

${ }^{6}$ Throughout this article, with the "surplus of volunteering", we refer to job candidates' higher probability of positive call-back due to volunteer work disclosed in their résumés.

${ }^{7}$ Because our study is based on a field experiment with no informed consent, we let the Ethical Committee of the Faculty of Economics and Business Administration of Ghent University review (and approve) this research. We based our question for approval on the in-depth discussion of the ethical aspects of correspondence experiments in Riach and Rich (2004)
} 
sent to vacancies in only one or a few specific occupations (with, potentially, a high (or low) treatment effect), we aimed to test the returns to volunteering with respect to hiring chances in multiple occupations (and, in relation to this, multiple sectors). Therefore, we created pairs of application templates (comprised of a résumé and a motivation letter) for jobseekers at two education levels. The middle-educated pair held a secondary education degree in commerce, and the high-educated pair held a bachelor's degree in office management. These degrees, obtained from the same type of school, allowed them to apply for almost all commercial and administrative positions at the ISCED 3 and ISCED 5 levels, ${ }^{8}$ respectively.

The two templates within each pair (which we labelled type ' $A$ ' and type ' $B$ ' applications) were, at the education level, identical concerning all job-relevant characteristics but differed in wording, fonts and formatting to prevent the employers from detecting the experiment. To ensure that our templates were realistic, example résumés and motivation letters from the Public Employment Agency of Flanders ("VDAB") were used and refined.

All fictitious applicants were single individuals born, living and studying in Antwerp, the largest city of Flanders, with approximately 503,000 inhabitants. The middle-educated individuals were 20 years old, and the high-educated were 23 years old. They graduated in June 2012. Between August 2012 and November 2014 (just before the start of our experiment), they were employed in an administrative position at the level of their educational degree. A reason for the termination of this first job was not provided in the applications.

In addition, the following characteristics were added to all fictitious applicants: a Flemish name and surname; ${ }^{9}$ an address (existing street name but non-existing

\footnotetext{
${ }^{8}$ ISCED stands for "International Standard Classification of Education". ISCED 3 refers to upper-secondary education (i.e., more specialised education that typically begins at age 15 or 16 years preparing; it prepares pupils for tertiary education, provides them with skills relevant to employment, or does both). ISCED 5 refers to the first stage of tertiary education (i.e., programmes with an educational content more advanced than those offered at ISCED leve 3 and ISCED level 4 (post-secondary non-tertiary education), which might be academically or practically oriented). ${ }^{9}$ In parallel with this field experiment, an analogous experiment was conducted with Turkish names to investigate whether prosocial engagement might reduce ethnic labour market discrimination (Baert and Vujić, 2015).
} 
house number) in a middle income neighbourhood; an email address and a mobile phone number (from leading providers); a date of birth in 1994 (middle-educated) or 1991 (high-educated); a gender (see Section 2.2); a Belgian nationality; very good Dutch, French and English language skills; very good office software skills; a driver's license; and the availability of a car. ${ }^{10}$

It is important to keep in mind that minimal differences between type $A$ and type $B$ application templates could not bias our results because the prosocial engagement as our treatment of interest was, for each vacancy, randomly assigned to these types, as discussed in the following subsection.

\subsection{Randomised Assignment of Treatment of Volunteering, Particular Combination of Volunteer Work and Gender}

Two job candidacies, one of type A and one of type B, were sent to each selected vacancy. Within these pairs of applicants, the mention of undertaken volunteer work was alternately assigned to either the type A template or the type B template. More specifically, volunteer work was mentioned in the résumés' "Other activities" section, in which it is common in Flanders to refer to memberships and engagements as sorts of "extracurricular" attainments.

Additionally, to measure the returns to prosocial engagement for different types and different doses of volunteer work, we alternately assigned one out of seven combinations of volunteer activities to the treated applicant. These seven options were based on all possible combinations of one, two or three engagements out of three potential activities. The first activity that was mentioned by a part of the treated applicants was "volunteer work at Poverello [a major life-saving food provider in Belgium] (preparing and disseminating meals, once per week)." The second potential activity was "volunteer work at Stichting tegen Kanker [a major cancer foundation in Belgium] (fundraising and supporting local activities on a frequent basis)." The last one was "equipment manager at Korfbal Club Artemis [a

\footnotetext{
${ }^{10}$ The résumé and motivation letter templates are available upon request.
} 
regional korfball club in Antwerp] (logistic support at main trainings and game days)." ${ }^{11}$ Consequently, the seven possible combinations that were alternately revealed by the treated applicants were: (i) volunteer at life-saving food provider; (ii) volunteer at cancer foundation; (iii) volunteer at sports club; (iv) volunteer at lifesaving food provider and cancer foundation; (v) volunteer at life-saving food provider and sports club; (vi) volunteer at cancer foundation and sports club, and (vii) volunteer at life-saving food provider, cancer foundation and sports club.

Finally, to obtain unbiased heterogeneous volunteering effects by gender, we alternated between female and male pairs of fictitious candidates. The gender of the candidates was indicated in the résumé by means of their name and gender. Their (typically male or female) name was also mentioned in their motivation letter.

\subsection{Vacancy Selection, Application and Call-Back}

We sent to genuine vacancies the resulting combinations of two application templates, two experimental identities, seven combinations of different types and doses of volunteer work, and two genders, with 12 to 36 hours in between and in an alternating order. More concretely, between December 2014 and April 2015, we tested randomly selected vacancies in the database of the Public Employment Agency of Flanders, the region's major job search channel, for which our (middle- or high-educated) pairs of applicants had the right classifications. In total, we sent out 576 applications; half of them were with middle-educated applicants, and the other half were with high-educated applicants.

Reactions from (real) employers to our fictitious candidacies were received by email and mobile phone voicemail. ${ }^{12}$ To minimise the hindrance for the employers, we immediately halted the selection procedure after receiving a positive call-back. All reactions obtained later than 40 days after the date of candidacy submission were not considered.

\footnotetext{
${ }^{11}$ This sports was chosen due to its high representation of both females and males.

12 The content of employers' responses is available upon request.
} 
In our analysis, we will distinguish between two definitions of positive call-back. Positive call-back sensu lato indicates that the applicant received (i) an invitation for an interview concerning the job for which she/he applied, (ii) a proposal of an alternative position, (iii) an inquiry to provide the employer with more information, or (iv) a general inquiry to contact the employer. Positive call-back sensu stricto indicates that the applicant was invited for an interview concerning the job for which she/he applied.

\section{The Results}

In this section, we present empirical insights based on the statistical examination of the experimentally gathered data. First, we report the positive call-back rates for the volunteering and non-volunteering fictitious candidates, pooled and separated by the gender of the candidate, her/his dose of prosocial engagement and the orientation of the sector of the vacancy. Second, we discuss an ordered logit regression analysis, which allows us to combine the broad and strict sense call-back outcome variables discussed in Section 2.3 and to measure an independent effect of the aforementioned candidate and vacancy characteristics in interaction with volunteer work on this combined call-back outcome.

\subsection{Bivariate Analysis}

Table 2 and Table 3 describe the experimentally gathered data. We present positive call-back rates for the volunteering and non-volunteering candidate within the submitted pairs of fictitious job candidacies. In Table 2 (Table 3) we list these outcomes for the broad-sense (strict-sense) definitions of positive call-back, respectively.

TABLE 2 ABOUT HERE.

TABLE 3 ABOUT HERE. 
Call-back outcomes with respect to all tested vacancies together are presented in Panel A of these tables. Overall, the volunteering candidates received a positive reaction in a broad sense (an invitation for a job interview) in $22.9 \%{ }^{13}(11.1 \%)$ of applications, whereas their non-volunteering counterparts obtained a positive reaction (an invitation) in only $15.6 \%$ (8.3\%) of cases. The Positive Call-Back Ratio (PCBR) in the seventh column of Table 2 is then calculated by dividing the former percentage by the latter. Consequently, the PCBR in a broad sense is approximately 1.467, whereas the PCBR in strict sense is 1.333 . These numbers indicate that the volunteering candidate within the pairs of fictitious candidates had a $46.7 \%$ higher probability of receiving any positive reaction and a 33.3\% higher probability of being invited for a job interview. The former statistic is significantly different from 1 at the $1 \%$ significance level. The latter is significant only at the $10 \%$ significance level, related to the lower level of variation in positive call-backs sensu stricto.

Somewhat surprisingly, this overall level of the hiring premium for prosocially engaged job candidates is comparable to the level of the premium of a nativesounding (versus a Turkish-sounding) name found within a comparable correspondence study in Flanders in 2011-2012 on ethnic discrimination (with a broad-sense PCBR of 1.319 and a strict-sense PCBR of 1.440; Baert et al., 2015). In addition, the surplus from volunteering is comparable to the surplus found for male applicants when applying for positions implying a first promotion in a comparable experiment on Sticky Floors in the Flemish labour market in 2013-2014 (with PCBRs of 1.229 and 1.500, respectively; Baert et al., forthcoming).

In what follows, we breakdown the PCBRs by several characteristics of the pairs of fictitious candidates. More concretely, we break down the total sample by (i) the education level of the pair, (ii) the pair's gender, (iii) the mention of a particular type of volunteer work by the treated pair member, and (iv) her/his total number of prosocial engagements mentioned. First, concerning the education level of the candidates, no substantial difference in the PCBR based on whether the candidates

\footnotetext{
${ }^{13} 0.229=(31+35) / 288$.
} 
applied with a secondary education degree or with a bachelor's degree is found. The PCBR in a broad sense is somewhat higher in magnitude for the middle-educated pairs but higher in significance for the high-educated pairs, ${ }^{14}$ whereas the PCBR in a strict sense is perfectly equal for the two subsamples. Second, our overall finding of a surplus for volunteering at first hiring decisions is clearly driven by the female pairs of candidates. For female candidates, the mention of a prosocial engagement increases the probability of a positive reaction by $70.4 \%$ and the probability of a job interview invitation by $62.5 \%$. For the subsample of male candidates, no unequal treatment based on prosocial engagement is found. This higher call-back premium for women contrasts with the research findings of Day and Devlin (1997) and Cozzi et al. (2013) mentioned in the introduction. Third, positive call-back rates are somewhat higher for pairs in which the treated candidate revealed (solely or among one or both of the two other prosocial activities) volunteering at the life-saving food provider or at the cancer foundation (compared to revealing volunteering at the korfball club). We will return to the significance of all these dimensions of heterogeneity in the premium of volunteering with respect to first hiring outcomes when we present our regression results in the next subsection.

In Panel $\mathrm{C}$ of Tables 2 and 3, the PCBRs are broken down by two vacancy characteristics: the sector (profit versus public and non-profit sectors) and the job posting agency (directly by the firm or via an interim office). First, we do not find evidence for our overall result to be driven by the subsample of vacancies tested in the public and non-profit sector. However, the subsample of fictitious job applications sent to vacancies in the public and non-profit sector turned out to be rather small (only ten percent of the total sample) ${ }^{15}$ to be conclusive about this dimension of heterogeneity. Nevertheless, it is clear that this finding does not support at all the employer preference channel underlying the observed higher rates

\footnotetext{
${ }^{14}$ This combination of findings can be explained by the higher probability of positive call-back for the high-educated (see Section 3.2), irrespective of their prosocial engagement, and ipso facto the higher level of variation in call-back for them compared to the middle-educated.

${ }^{15}$ Based on an assessment of 200 random vacancies in the database of the Public Employment Service of Flanders, ten percent of vacancies from the public and non-profit sector appears to be a representative proportion.
} 
of prosocially engaged employees in the public and non-profit sector mentioned in the introduction. Consequently, this finding is more consistent with the idea of prosocial workers sorting themselves into these sectors, thus aligning our results with the literature on self-selection and sorting in the labour market (Besley and Ghatak, 2005; Gregg et al. 2011; Lagarde and Blaauw, 2014). Second, the breakdown by the vacancy posting agency does not reveal heterogeneity in the volunteering premium by this dimension.

\subsection{Multivariate Analysis}

Because the volunteering and non-volunteering candidates were randomly assigned within our pairs of applications, regressing positive call-back on an indicator of being a volunteering candidate yields exactly the same empirical patterns as those based on Panel A of Tables 2 and 3. Moreover, because these variables were randomly assigned between pairs, regressions on interactions between volunteering and, among other candidate characteristics, the gender of the candidate and her/his particular volunteer work should lead to the same empirical pattern as the one in Panel B of Tables 2 and 3, at least when the sample size approaches infinity. However, the actual size of our sample is not infinite. Consequently, some of the variables randomly assigned between pairs may happen to correlate with vacancy characteristics such as the sector or the use of an interim office. Moreover, by construction, the type and dose of the mentioned prosocial engagement are correlated with each other. ${ }^{16}$ To control for these sources of correlation, we further analyse the experimental data by a regression analysis.

Additionally, by means of an ordered logistic regression, we are able to combine the variation in the two studied outcomes, i.e., the probability of getting immediately invited for an interview after applying for a job and the probability of getting any positive reaction. Therefore, we construct a dependent variable, which is 2 in cases in which the candidate is immediately invited to a job interview, 1 in

\footnotetext{
${ }^{16}$ In case one (two) ((three)) engagement(s) is (are) mentioned, the probability for each particular type to be included in the résumé is $33.3 \%$ (66.7\%) ((100.0\%)).
} 
cases in which she/he receives any other (broad-sense) positive reaction, and 0 in cases in which she/he receives no positive reaction at all.

Table 4 presents our model estimates as odds ratios. We regress the aforementioned categorical dependent variable on various sets of key and control variables, included as such (when not invariant for control applicants) and in interaction with disclosing a prosocial engagement. To ensure comparability of the regression results, all variables except for the one indicating treated individuals are normalised by subtracting their mean among the subpopulation of all prosocially engaged candidates. Lastly, because two applicants contacted the same firm, their probability of receiving a positive reaction is correlated. Therefore, standard errors are corrected for the clustering of the observations at the vacancy level.

In Model (1), we regress positive call-back on a dummy indicating only volunteer work. In line with Panel A of Tables 2 and 3, we obtain an odds ratio that is significantly higher than 1. More concretely, we find that the odds of a more beneficial outcome (invitation versus any other positive reaction and any other positive reaction versus no positive reaction at all) is $58.0 \%$ higher when a candidate reveals prosocial engagement. In Model (2), we add interactions between volunteer work and the variables by which we broke down our data in Panel B of Tables 2 and 3. More concretely, we add interactions with indicators of high-educated candidates, male candidates, candidates who reveal engagement in a cancer organisation, candidates who reveal engagement at a korfball sports club, candidates with two engagements, and candidates with three engagements. We find a significant interaction only with respect to gender: The odds ratio comparing the positive call-back rates for candidates with and without volunteer work is $50.2 \%$ lower in cases in which volunteer work is performed by males. ${ }^{17}$ In addition, not surprisingly, we observe significantly higher positive call-back rates for the high-

\footnotetext{
17 The fact that we find, albeit to a non-significant extent, higher odds ratios for those with more prosocial engagements-whereas PCBRs in Tables 2 and 3 were not higher in magnitude among the subsample of candidates with three prosocial engagements (compared to those with one or two engagements)-is due to the aforementioned positive correlation between the volunteering type dummies and the number of volunteer activities.
} 
educated candidates (without interaction with prosocial behaviour). Finally, in Model (3), we extend the set of variables included as such and in interaction with prosocial engagement with indicators for vacancies in the public and non-profit sector and for vacancies posted by interim offices. Consistent with our discussion of Panel $\mathrm{C}$ of Tables 2 and 3, no significant odds ratios are found with respect to these interactions. In addition, the introduction of these additional variables hardly affects the aforementioned overall effect of disclosing volunteer work activities and the interaction effect with respect to gender.

To test the robustness of the presented regression results, we also estimated (i) binary logit models and (ii) linear probability models controlling for fixed effects at the vacancy level for both call-back outcomes separately. The results for these models led to the same empirical conclusions and are available upon request.

\section{Conclusion}

In this study, we contributed to the literature on micro-economic returns to volunteering in the labour market. Whereas all previous contributions to this literature relied on survey data, in which selection into volunteer work is not random, we adopted a field experimental approach. More concretely, we sent pairs of fictitious job applications to genuine vacancies in Belgium. For every vacancy, a treatment of prosocial engagement was randomly assigned to one pair member. By analysing employers' call-back, we found that the causal effect of disclosing prosocial activities on hiring opportunities is, in both statistical and economic terms, substantial. Volunteering candidates were found to have a $46.7 \%$ higher probability of receiving any positive reaction and a $33.3 \%$ higher probability of being immediately invited for a job interview.

In addition, our experimental approach allowed us to provide novel insights into why and when (in particular) working for free might pay off. First, because strict equivalence between our fictitious applicants was ensured, and because by 
construction, they applied for positions with an employer outside of their network, the positive volunteering premium that we estimated suggests that employers' taste for and interpretation of (the signal of) prosocial engagement plays a crucial role in the robustly positive relationship between volunteering and labour market success found in the literature. Second, because in addition to the within-pair randomisation of prosocial engagement, the female or male gender and different combinations of three types of prosocial engagement were randomly assigned between our pairs of fictitious job applicants, we were able to estimate heterogeneity in the volunteering premium by the gender of the candidate and her/his dose of prosocial engagement. We found that women had larger returns to volunteer experience than men. This finding might indicate that the higher volunteering premium for men, which is usually found based on survey data, merely reflects the fact that males select themselves into types of volunteering that are more rewarded in the labour market (such as service clubs). In addition, because we tested both commercial and noncommercial vacancies, we were able to explore whether the general finding that volunteer participation is higher in the public and non-profit sector than in the private sector is driven by differences in employers' preferences (for socially motivated workers) between these sectors. However, based on our experimentally gathered data, we cannot reject that the volunteering premium is equal in the commercial and non-commercial sectors. This finding is consistent with the idea that prosocial workers sort themselves into the latter sectors.

We end by acknowledging two research limitations inherent to our experimental design. The most important limitation of this study is its focus on a particular-but determining-labour market outcome, i.e., the initial hiring decisions of employers (outside candidates' network). Because we simply investigate effects on first callbacks, we cannot translate our findings into divergences in final job or wage offers. Therefore, in comparison with the former contributions to the literature on volunteering and employment outcomes, we completely eliminate the non-random selection in volunteer work at the cost of giving up on scope. However, Bertrand and Mullainathan (2004) have argued that one can expect that reduced interview rates translate into reduced job and wage offers. Moreover, based on field experiments 
testing all phases of the selection process, Bendick et al. (1999) and Cédiey et al. (2008) reported that when they conducted their study, approximately three fourths of age discrimination in the United States and approximately five sixths of ethnic discrimination in France occurred in the first phase of the hiring process.

A second limitation has further repercussions for the generalisability of our findings. We measure only the (potential) surplus of volunteering for young candidates within jobs in administrative and commercial occupations submitted to the Public Employment Agency of Flanders. Although compared to former correspondence experiments (see Section 2.1), this limitation is less acute in our design, it is still possible that the surplus of volunteering is more or less present in other occupations than those covered in our study. However, because this limitation should cause a similar shift in the volunteering surplus irrespective of candidate and vacancy characteristics, this fact should not bias the conclusions with respect to heterogeneity in the relative surplus of volunteering by, for instance, the gender of the candidate, the dose of prosocial engagement and the sector of the organisation. The same is true for the first mentioned limitation.

\section{References}

Anderson, N., Lievens, F., Van Dam, K., Ryan, A. M. (2004): Future perspectives on employee selection: Key directions for future research and practice. Applied Psychology, 53, 487-501.

Angrist, J. D., Graddy, K., Imbens, G. (2000): The Interpretation of Instrumental Variables Estimators in Simultaneous Equations Models with an Application to the Demand for Fish. Review of Economic Studies, 67, 499-527.

Arrow, K. J. (1973): The Theory of Discrimination. In Ashenfelter, O., Rees, A. (eds.): Discrimination in Labor Markets. Princeton: Princeton University Press.

Baert, S., Cockx, B., Gheyle, N., Vandamme, C. (2015): Is There Less Discrimination in Occupations Where Recruitment Is Difficult? ILR Review, 68, 467500 . 
Baert, S., De Pauw, A.-S., Deschacht, N. (forthcoming): Do Employer Preferences Contribute to Sticky Floors? ILR Review.

Baert, S., Vujić, S. (2015): Prosocial Engagement: An Ethnic Discrimination Reducing Device? Mimeo.

Bandiera, O. (2015) Incentives for Public Service Delivery. Keynote lecture at the Annual Conference of the European Association of Labour Economists of 2014.

Bandiera, O., Barankay, I., Rasul, I. (2011): Field Experiments with Firms. Journal of Economic Perspectives, 25, 63-82.

Baron, J. N., Hannan, M. T. (2002): Organizational Blueprints for Success in HighTech Start-Ups: Lessons from the Stanford Project on Emerging Companies. California Management Review, 44, 7-36.

Barrick, M. R., Mount, M. K. (1991): The big five personality dimensions and job performance: a meta-analysis. Personnel Psychology, 44, 1-26.

Becker, G. S. (1957): The Economics of Discrimination. Chicago: University of Chicago Press.

Becker, G. S. (1964). Human Capital: A Theoretical and Empirical Analysis, with Special Reference to Education. New York: National Bureau of Economic Research.

Becker, G. S. (1965): A theory of the allocation of time. Economic Journal, 75, 493-517.

Bekkers, R. (2005): Participation in voluntary associations: Relations with resources, personality, and political values. Political Psychology, 26, 439-454.

Bendick, M., Brown, L. E., Wall, K. (1999): No Foot in the Door: An Experimental Study of Employment Discrimination Against Older Workers. Journal of Aging \& Social Policy, 10, 5-23.

Bertrand, M., Mullainathan, S. (2004): Are Emily and Greg more employable than Lakisha and Jamal? A field experiment on labor market discrimination. American Economic Review, 94, 991-1013. 
Besley, T., Ghatak, M. (2005): Competition and incentives with motivated agents. American Economic Review, 95, 616-636.

Binder, M., Freytag, A. (2013): Volunteering, subjective well-being and public policy. Journal of Economic Psychology, 34, 97-119.

Borghans, L., ter Weel, B., Weinberg, B. A. (2008): Interpersonal Styles and Labour Market Outcomes. Journal of Human Resources, 43, 815-858.

Carpenter, J. P., Myers, C. K. (2010): Why Volunteer? Evidence on the Role of Altruism, Reputation, and Incentives. Journal of Public Economics, 94, 911-920.

Cédiey, E., Foroni, F., Garner, H. (2008): Discrimination à l'embauche fondée sur I'origine à l'encontre des jeunes français(e)s peu qualifié(e)s. Dares Premières Infos Premières Synthèses, 06.3.

Costa, P.T. Jr., McCrae, R. R. (1992): Revised NEO Personality Inventory (NEO-PIR) and NEO Five-Factor Inventory (NEO-FFI) manual. Odessa: Psychological Assessment Resources.

Cozzi, G., Mantovan, N., Sauer, R. M. (2013): Does It Pay to Work for Free? Wage Returns and Gender Differences in the Market for Volunteers. IZA Discussion Paper Series, 7697.

Day, K. M., Devlin, R. A. (1997): Can volunteer work help explain the male-female earnings gap? Applied Economics, 29, 707-721.

Day, K. M., Devlin, R. A. (1998): The payoff to work without pay: volunteer work as an investment in human capital. Canadian Journal of Economics, 31, 1179-1191.

Dittrich, M., Mey, B. (2015): Gender differences in volunteer activities: Evidence from German survey data. Economics Bulletin, 35, 349-360.

Elshaug, C., Metzer, J. (2001): Personality and volunteering: A review of the literature. Journal of Social Psychology, 141, 752-763.

Eriksson, S., Rooth, D.-O. (2014): Do Employers Use Unemployment as a Sorting Criterion When Hiring? Evidence from a Field Experiment. American Economic Review, 104, 1014-1039. 
Francois, P., Vlassopoulos, M. (2008): Pro-social motivation and the delivery of social services. CESifo Economic Studies, 54, 22-54.

Fortin, N. M. (2008): The Gender Wage Gap among Young Adults in the United States: The Importance of Money versus People. Journal of Human Resources, 43, 884-918.

Granovetter, M. S. (1973): The Strength of Weak Ties. American Journal of Sociology, 78, 1360-1380.

Gregg, P., Grout, P. A., Ratcliffe, A., Smith, S., Windmeijer, F. (2011): How important is pro-social behaviour in the delivery of public services? Journal of Public Economics, 95, 758-766.

Hackl, F., Halla, M., Pruckner, G. J. (2007): Volunteering and Income - The Fallacy of the Good Samaritan? Kyklos, 60, 77-104.

Heineck, G. (2011): Does it Pay to Be Nice? Personality and Earnings in the United Kingdom. ILR Review, 64, 1020-1038.

Jacobsen, K., Eika, K., Helland, L., Lind, J., Nyborg, K. (2011): Are nurses more altruistic than real estate brokers? Journal of Economic Psychology, 32, 818-831.

Kolstad, J. R., Lindkvist, I. (2013): Pro-social preferences and self-selection into the public health sector: evidence from an economic experiment. Health Policy and Planning, 28, 320-327.

Kroft, K., Lange, F., Notowidigdo, M. J. (2013): Duration Dependence and Labor Market Conditions: Evidence from a Field Experiment. Quarterly Journal of Economics, 128, 1123-1167.

Lagarde, M., Blaauw, D. (2014): Pro-social preferences and self-selection into jobs: Evidence from South African nurses. Journal of Economic Behavior \& Organization, 107, 136-152.

Leete, L. (2000): Wage equity and employee motivation in nonprofit and forprofit organizations. Journal of Economic Behavior \& Organization, 43, 423-446. 
Meier, S., Stutzer, A. (2008): Is Volunteering Rewarding in Itself? Economica, 75, 39-59.

Mincer, J. (1958): Investment In Human Capital and the Personal Income Distribution. Journal of Political Economy, 66, 281-302.

OECD (2015): Skills for Social Progress. Paris: OECD.

Pager, D. (2007): The use of field experiments for studies of employment discrimination: contributions, critiques, and directions for the future. Annals of the American Academy of Political and Social Science, 609, 104-133.

Prouteau, L., Wolff, F.-C. (2006): Does volunteer work pay off in the labor market? Journal of Socio-Economics, 35, 992-1013.

Riach, P. A., Rich, J. (2002): Field Experiments of Discrimination in the Market Place. Economic Journal, 112, 480-518.

Riach, P. A., Rich, J. (2004): Deceptive Field Experiments of Discrimination: Are They Ethical? Kyklos, 57, 457-470.

Rotolo, T., Wilson, J. (2006): Employment sector and volunteering: the contribution of nonprofit and public sector workers to the volunteer labour force. Social Science Quarterly, 47, 21-40.

Sauer, R. M. (2015): Does it Pay for Women to Volunteer? International Economic Review, 56, 537-564.

Schneider, B. (1987): The people make the place. Personnel Psychology, 40, 437453.

Tett, R. P., Jackson, D. N., Rothstein, M. (1991): Personality measures as predictors of job performance: A meta-analytic review. Personnel Psychology, 44, $703-742$.

Uysal, S. D., Pohlmeier, W. (2011): Unemployment duration and personality. Journal of Economic Psychology, 32, 980-992. 
Figure 1. Fraction of Individuals at Work for Voluntary or Charitable Organisations At Least Once Every Six Months by Country in Europe (in 2006/2007 and 2012/2013)

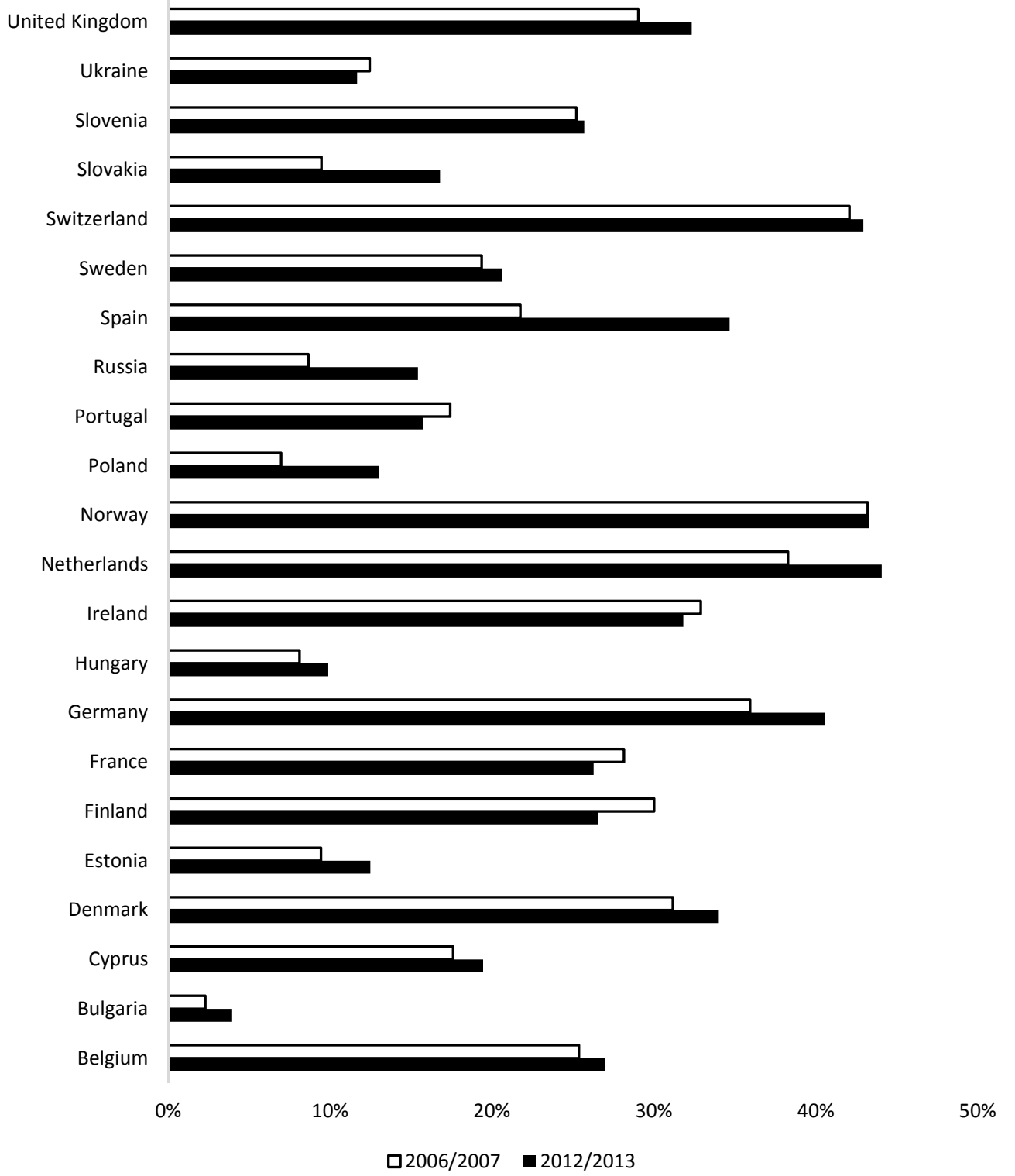

Notes. Source: Own calculations based on the question "In the past 12 months, how often did you get involved in work for voluntary or charitable organisations?" in the third round (conducted in 2006/2007) and sixth round (conducted in 2012/2013) of the European Social Survey. Only countries that were surveyed in both rounds are included. 
Table 1. Micro-Economic Returns to Volunteering in the Labour Market: Literature Review

\begin{tabular}{|c|c|c|c|}
\hline Study & $\begin{array}{l}\text { Country of } \\
\text { analysis }\end{array}$ & Main result(s) & Methodological approach \\
\hline $\begin{array}{l}\text { Cozzi et al. } \\
\text { (2013) }\end{array}$ & $\begin{array}{l}\text { United } \\
\text { Kingdom }\end{array}$ & $\begin{array}{l}\text { A (past or current) prosocial engagement increases current and future wages by } \\
94.7 \% \text { for men and } 87.5 \% \text { for women. OLS estimates yield substantially lower } \\
\text { returns. }\end{array}$ & $\begin{array}{l}\text { IV modelling (using rainfall across area districts as an instrument for } \\
\text { volunteer activity) and controlling for individual fixed effects on longitudinal } \\
\text { family survey data. }\end{array}$ \\
\hline $\begin{array}{l}\text { Day and Devlin } \\
\text { (1997) }\end{array}$ & Canada & $\begin{array}{l}\text { A (past or current) prosocial engagement increases current and future wages by } \\
21.5 \% \text { for men and } 11.2 \% \text { for women. }\end{array}$ & $\begin{array}{l}\text { OLS regressions controlling for observables on cross-sectional survey data } \\
\text { of volunteer activity. }\end{array}$ \\
\hline $\begin{array}{l}\text { Day and Devlin } \\
\text { (1998) }\end{array}$ & Canada & $\begin{array}{l}\text { A (past or current) prosocial engagement in the current year increases earnings in } \\
\text { this year by } 6.6 \% \text {. }\end{array}$ & $\begin{array}{l}\text { OLS regressions controlling for observables on cross-sectional survey data } \\
\text { of volunteer activity. }\end{array}$ \\
\hline $\begin{array}{l}\text { Hackl et al. } \\
(2007)\end{array}$ & Austria & A current prosocial engagement increases current earnings by $18.5 \%$. & $\begin{array}{l}\text { IV modelling (using engagement in a club during youth and having a } \\
\text { volunteering partner as an instrument for volunteer activity) on cross- } \\
\text { sectional family survey data. }\end{array}$ \\
\hline $\begin{array}{l}\text { Prouteau and } \\
\text { Wolff (2006) }\end{array}$ & France & $\begin{array}{l}\text { A current prosocial engagement (in which one performs managerial tasks) increases } \\
\text { current earnings by } 5.5 \% \text { in the public sector and decreases current earnings by } \\
1.7 \% \text { in the private sector. }\end{array}$ & $\begin{array}{l}\text { Bivariate probit estimations with endogenous switching on cross-sectional } \\
\text { family time allocation survey data. }\end{array}$ \\
\hline Sauer (2015) & $\begin{array}{l}\text { United } \\
\text { States }\end{array}$ & $\begin{array}{l}\text { An extra year of (past or current) prosocial engagement increases wage offers in } \\
\text { future full-time (part-time) work by } 2.6 \%(8.5 \%) \text { for women between age } 25 \text { and } \\
55 \text {. }\end{array}$ & $\begin{array}{l}\text { Structural modelling (discrete choice dynamic programming) on } \\
\text { longitudinal family survey data. }\end{array}$ \\
\hline
\end{tabular}


Table 2. The Probability of Positive Call-Back in a Broad Sense: Descriptive Analysis

\begin{tabular}{|c|c|c|c|c|c|c|c|}
\hline Data selection & Jobs & $\begin{array}{l}\text { Neither candidate } \\
\text { positive call-back }\end{array}$ & $\begin{array}{l}\text { Both candidates } \\
\text { positive call-back }\end{array}$ & $\begin{array}{c}\text { Only prosocial } \\
\text { candidate positive } \\
\text { call-back }\end{array}$ & $\begin{array}{c}\text { Only control } \\
\text { candidate positive } \\
\text { call-back }\end{array}$ & PCBR & $\mathrm{t}$ \\
\hline \multicolumn{8}{|l|}{ A. Full sample } \\
\hline Full sample & 288 & 208 & 31 & 35 & 14 & $1.467^{* * *}$ & 3.043 \\
\hline \multicolumn{8}{|c|}{ B. Subsamples by candidates' characteristics } \\
\hline Middle-educated & 144 & 124 & 7 & 10 & 3 & $1.700^{*}$ & 1.961 \\
\hline High-educated & 144 & 84 & 24 & 25 & 11 & $1.400^{* *}$ & 2.371 \\
\hline Female gender & 144 & 89 & 18 & 28 & 9 & $1.704^{* * *}$ & 3.224 \\
\hline Male gender & 144 & 119 & 13 & 7 & 5 & 1.111 & 0.576 \\
\hline Volunteer at life-saving food provider & 176 & 125 & 18 & 24 & 9 & $1.556 * * *$ & 2.656 \\
\hline Volunteer at cancer foundation & 176 & 129 & 19 & 22 & 6 & $1.640^{* * *}$ & 3.097 \\
\hline Volunteer at sports club & 176 & 125 & 23 & 18 & 10 & 1.242 & 1.517 \\
\hline One prosocial engagement & 96 & 70 & 8 & 13 & 5 & $1.615^{*}$ & 1.912 \\
\hline Two prosocial engagements & 144 & 105 & 17 & 15 & 7 & $1.333^{*}$ & 1.717 \\
\hline Three prosocial engagements & 48 & 33 & 6 & 7 & 2 & $1.625^{*}$ & 1.699 \\
\hline \multicolumn{8}{|l|}{ C. Samples by vacancy characteristics } \\
\hline Profit sector & 262 & 188 & 27 & 34 & 13 & $1.525^{* * *}$ & 3.114 \\
\hline Public and non-profit sector & 26 & 20 & 4 & 1 & 1 & 1.000 & 0.000 \\
\hline Firm as posting agency & 256 & 191 & 27 & 27 & 11 & $1.421^{* * *}$ & 2.625 \\
\hline Interim office as posting agency & 32 & 17 & 4 & 8 & 3 & 1.714 & 1.540 \\
\hline
\end{tabular}
\begin{tabular}{l}
\hline \hline Notes. In line with the literature, we calculate the Positive Call-Back Ratio (PCBR) by dividing the percentage of applications for which prosocial candidates received a positive call-back by the \\
corresponding percentage for the control candidates. The t-test for the PCBR tests the null hypothesis that these percentages are the same for candidates from both groups. Standard errors are
\end{tabular} corrected for clustering of the observations at the job posting level. ${ }^{* * *}\left({ }^{* *}\right)((*))$ indicates significance at the $1 \%(5 \%)((10 \%))$ significance level. 
Table 3. The Probability of Positive Call-Back in a Strict Sense: Descriptive Analysis

\begin{tabular}{|c|c|c|c|c|c|c|c|}
\hline Data selection & Jobs & $\begin{array}{l}\text { Neither candidate } \\
\text { positive call-back }\end{array}$ & $\begin{array}{l}\text { Both candidates } \\
\text { positive call-back }\end{array}$ & $\begin{array}{c}\text { Only prosocial } \\
\text { candidate positive } \\
\text { call-back }\end{array}$ & $\begin{array}{c}\text { Only control } \\
\text { candidate positive } \\
\text { call-back }\end{array}$ & PCBR & $\mathrm{t}$ \\
\hline \multicolumn{8}{|l|}{ A. Full sample } \\
\hline Full sample & 288 & 249 & 17 & 15 & 7 & $1.333^{*}$ & 1.711 \\
\hline \multicolumn{8}{|c|}{ B. Subsamples by candidates' characteristics } \\
\hline Middle-educated & 144 & 135 & 5 & 3 & 1 & 1.333 & 1.000 \\
\hline High-educated & 144 & 114 & 12 & 12 & 6 & 1.333 & 1.419 \\
\hline Female gender & 144 & 114 & 12 & 14 & 4 & $1.625^{* *}$ & 2.396 \\
\hline Male gender & 144 & 135 & 5 & 1 & 3 & 0.750 & 1.000 \\
\hline Volunteer at life-saving food provider & 176 & 149 & 12 & 10 & 5 & 1.294 & 1.294 \\
\hline Volunteer at cancer foundation & 176 & 154 & 9 & 9 & 4 & 1.385 & 1.390 \\
\hline Volunteer at sports club & 176 & 152 & 11 & 8 & 5 & 1.188 & 0.831 \\
\hline One prosocial engagement & 96 & 84 & 5 & 5 & 2 & 1.429 & 1.136 \\
\hline Two prosocial engagements & 144 & 124 & 9 & 8 & 3 & 1.417 & 1.514 \\
\hline Three prosocial engagements & 48 & 41 & 3 & 2 & 2 & 1.000 & 0.000 \\
\hline \multicolumn{8}{|l|}{ C. Samples by vacancy characteristics } \\
\hline Profit sector & 262 & 225 & 15 & 15 & 7 & $1.364 *$ & 1.712 \\
\hline Public and non-profit sector & 26 & 24 & 2 & 0 & 0 & 1.000 & 0.000 \\
\hline Firm as posting agency & 256 & 225 & 17 & 10 & 4 & 1.286 & 1.609 \\
\hline Interim office as posting agency & 32 & 24 & 0 & 5 & 3 & 1.667 & 0.701 \\
\hline
\end{tabular}

Notes. In line with the literature, we calculate the Positive Call-Back Ratio (PCBR) by dividing the percentage of applications for which prosocial candidates received a positive call-back by the corresponding percentage for the control candidates. The t-test for the PCBR tests the null hypothesis that these percentages are the same for candidates from both groups. Standard errors are corrected for clustering of the observations at the job posting level. $*^{* *}(* *)((*))$ indicates significance at the $1 \%(5 \%)((10 \%))$ significance level. 
Table 4. The Odds of Positive Call-Back: Ordered Logit Estimates

\begin{tabular}{lccc}
\hline \hline & $(1)$ & $(2)$ & $(3)$ \\
\hline Prosocial & $1.580^{* * *}(0.242)$ & $1.536^{* *}(0.266)$ & $1.536^{* *}(0.268)$ \\
Prosocial x High-educated (normalised) & & $0.970(0.350)$ & $0.925(0.339)$ \\
Prosocial x Male gender (normalised) & & $0.498^{* *}(0.160)$ & $0.512^{* *}(0.166)$ \\
Prosocial x Volunteer at cancer foundation (normalised) & & $0.800(0.321)$ & $0.808(0.323)$ \\
Prosocial x Volunteer at sports club (normalised) & & $0.859(0.345)$ & $0.849(0.340)$ \\
Prosocial x Two prosocial engagements (normalised) & $1.192(0.456)$ & $1.204(0.461)$ \\
Prosocial x Three prosocial engagements (normalised) & & $1.795(1.106)$ & $1.848(1.146)$ \\
Prosocial x Public and non-profit sector (normalised) & & & $0.701(0.274)$ \\
Prosocial x Interim office as posting agency (normalised) & & & $1.297(0.731)$ \\
High-educated (normalised) & & $0.344^{* * *}(1.695)$ & $4.346 * *(1.733)$ \\
Male gender (normalised) & & & $0.570(0.201)$ \\
Public and non-profit sector (normalised) & & & $1.489(0.826)$ \\
Interim office as posting agency (normalised) & & 576 & $1.040(0.536)$ \\
\hline Observations & 576 & 576
\end{tabular}

Notes. The presented statistics are odds ratios based on an ordered logistic regression. The dependent variable is 2 in the case that the candidate is immediately invited to a job interview, 1 in the case that she/he receives any other positive reaction and 0 in the case that she/he receives no positive reaction at all. All independent variables except for the one indicating prosocial engagement, are normalised by subtracting their mean among the subpopulation of all prosocially engaged candidates. Standard errors, corrected for clustering at the job posting level, are between parentheses. *** $(* *)((*))$ indicates significance at the $1 \%(5 \%)((10 \%))$ significance level. 